\title{
Notas marginais de Mário de Andrade ao livro Mitos de nosso tempo, de Alceu Amoroso Lima (Rio de Janeiro: Livraria José Olympio Editora, 1943)
}

\author{
Luciano Costa Santos
}

p. 1. Dedicatória de Alceu Amoroso Lima: "Ao caro amigo Mário de Andrade, com a velha admiração do Tristão. Março 1943”

(1) p. 1. Nota de Mário de Andrade: anotação abaixo e à margem esquerda do título do livro Mitos de nosso tempo: “Arte - p. 85 e s".

(2) p. 3: folha de rosto ${ }^{2}$. Nota MA: anotação à margem esquerda de “1943” (ano da edição do livro): “卢60”.

(3) p. 37-38: Cap. III (“A nova mística”). Nota MA: cruzeta à margem direita do parágrafo:

Na definição dada ao Mito não se considera esse elemento valor como indistinto. Não se trata, para haver um mito verdadeiro, de atribuir qualquer valor a qualquer realidade. Trata-se de atribuir um valor absoluto a uma entidade relativa. Trata-se pois de uma inversão de valores. Um valor absoluto é o que constitui uma medida dos demais, e um padrão pelo qual os outros são aferidos. É uma hierarquia da qual se torna o mais graduado. Mais do que isso. O valor absoluto não é da mesma natureza que os valores relativos. Sua natureza é permanente, ao passo que a dos demais é passageira. Ele fica, os outros passam. Vale por si, os demais apenas como participação.

(4) p. 52-53: Cap. V (“A riqueza”). Nota MA: traço vertical à margem esquerda do trecho: "Aliás não seria difícil mostrar que o mitolo-

1 N. E.: Material utilizado por Luciano Santos no artigo Mário-Alceu: um diálogo marginal (Mário de Andrade leitor de Alceu Amoroso Lima), também publicado nesta revista.

2 Os termos sublinhados indicam dúvida 
gismo não é apenas a religião de nossos tempos mas ainda a de todas as épocas históricas em que se desintegra uma civilização." Expoente (1) à margem esquerda do trecho citado, para comentário às margens superior e inferior da p. 52, concluindo na margem inferior da página seguinte:

Aqui, a tese me parece que se fragiliza por completo. Na realidade o A. não está mais estudando e julgando enquanto filósofo e sociólogo, mas em função do seu Catolicismo. De um catolicismo que julga a chamada (meu Deus!) "Civilização Cristã”, como tendo alcançado o seu apogeu na Idade Média. Isto é: uma civilização não mais definida e compreendida pelo que é, em si, mas como expressão da doutrina de Cristo. Ora, não há dúvida que o Cristianismo, ou melhor, Cristo, deu origem a uma civilização. Mas da qual, em seguida, ele não teve a culpa! Negar o Renascimento, por exemplo, como uma das expressões máximas da Civilização Cristã, é simplesmente confundir civilização e cultura (Kultur, sociologicamente) com uma determinada religião. - Não é tudo. Se observarmos outras civilizações (depois desta frase do A.), a grega, por ex. ou a chinesa, vemos que certos "mitos" por ele enumerados, foram princípios básicos, não da "desintegração" dessas civilizações, mas dos períodos de formação e plenitude. A "classe" por ex., na Grécia. A “cultura” na China.

(5) p. 55: Cap. V (“A riqueza"). Nota MA: chave e exclamação à margem esquerda do trecho:

O fim completo do mito da pecúnia seria a sua transformação em mitos espirituais ou pelo menos intelectuais ou então a sua correção pelo verdadeiro sentimento, em face da fortuna, que uma sã filosofia não mitológica, coloca no ponto subordinado que lhe cabe, na harmonia geral dos seres e dos sentimentos.

(6) p. 59: Cap. V ("A riqueza"). Nota MA: traço sublinhando o termo "decadència" no trecho:

Foi com o Estado Nacional, e a introdução dos novos ideais socialistas ou com a consciência de uma justiça social imanente até então 
pouco considerada - que o mito da pecúnia começou a sua fase de decadência e de substituição por mitos de outra natureza.

Anotação do termo "transformação" à margem direita do termo sublinhado.

(7) p. 63: Cap. VI (“A técnica”). Nota MA: expoente (1) à margem esquerda do trecho:

Mais do que nos romancistas, porém, é nos povos penetrados da mística revolucionária e para quem a Revolução é um Mito, que o culto da máquina se desenvolveu e onde o mito tecnológico encontrou um terreno mais favorável para se desenvolver, em virtude justamente do grau de atraso mental das populações.

Comentário à margem inferior da página:

Tudo isto (e F. Müller também) é absurdo, duma facilidade larvar. Os russos careciam se defender. Todo o mundo estava e está contra a URSS. Haviam de atirar trigo e florinhas silvestres contra balas de canhão, bloqueio econômico e o diabo? E como o autor acomoda o caso do Japão, faz mais de século?!...

[NB: René Fülöp Müller é o autor citado por Alceu Amoroso Lima na nota (3), p. 63-64.]

(8) p. 64: Cap. VI (“A técnica”). Nota MA: traço em curva descendente às margens superior e esquerda do trecho:

Embora seja nos povos mais civilizados e mais evoluídos que os mitos tenham condições mais favoráveis ao seu aparecimento. $\mathrm{O}$ mito nasce de um excesso de civilização, mas se espalha mais facilmente por deficiência de civilização, como a chama nasce do fogo e se propaga na palha.

Comentário à margem superior da página: “Não há dúvida!!! A Alemanha, a Itália, os países nórdicos com seus quis[?] - de linguas[?] ... E a máquina é... inglesa, o A. já disse atrás...”

(9) p. 87: Cap. VIII (“A cultura”). Nota MA: traço vertical à margem direita do trecho: 
O termo Cultura, por natureza ligado a uma tarefa de ordem pedagógica, foi pouco a pouco assumindo uma importância transcendente a todos os domínios especializados de que nos vimos ocupando de modo sumário. E de modo realmente muito sumário, pois o que desejamos é indicar caminhos e situar os problemas, cada um dos quais admite toda espécie de desenvolvimentos e comprovações ulteriores.

(10) p. 97: Cap. IX (“O número"). Nota MA: traço em chave e expoente (1) à margem direita do trecho:

Há, pois, de momento um surto grandioso de idealismo democrático que conseguiu pelo menos essa coisa magnífica - levantar um povo penetrado de comodismo e devorado pelo mito da técnica ou da riqueza, em nome de um mito muito mais nobre, pois que baseado no desinteresse e no sacrifício, como seja o Mito político democrático.

Comentário à margem inferior: "Eis o tipo do que seja fazer história idealista: sem Pearl Harbour e o mito da traição, sem a 'atrapalhação' que o Eixo estava trazendo aos interesses econômicos dos EEUU, queria ver o ianque 'levantado'!”

(11) p. 102: Cap. IX ("O número"). Nota MA: traço sublinhando a frase: "E sobre ambos repousa a salvação da humanidade.", do trecho: "Trata-se, para a mística revolucionária de criar um novo-homem e uma nova-civilização. E sobre ambos repousa a salvação da humanidade.” Expoente (1) à margem esquerda da frase sublinhada, para comentário à margem inferior: "Exagero de uma parcialidade de sectário. O A. confunde ou finge confundir a ideologia comunista com a demagogia comunista. E ‘salvação da humanidade’ é o que propõem todas as demagogias.”

(12) p. 108: Cap. X ("A classe"). Nota MA: traço vertical à margem esquerda do trecho:

Só as circunstâncias porém, e as alianças obrigam a um recuo de publicidade que é de ordem puramente estratégica. Esse recuo chegou ao ponto de aceitar, no tratado de aliança com a Inglaterra, o repúdio oficial a toda propaganda fora das fronteiras, nos domí- 
nios do aliado. Bem sabemos a precariedade dos tratados numa hora de predominância absoluta da Força sobre o Direito, nas relações entre indivíduos e entre nações. Stalin resolve as dificuldades, à medida que se apresentam, sem para isso se embaraçar em preconceitos de qualquer espécie. Nem por isso cede uma linha nas suas convicções profundas, nem perde a vantagem adquirida de uma mística que avassalou e galvanizou todo um povo e lhe permitiu realizar façanhas militares extraordinárias, como as que vem empreendendo há um ano. Não devemos desconhecer que, no cerne dessa resistência épica dos russos ao invasor, estão sentimentos profundos como o da justiça imanente da causa por que se batem, traídos que foram pelos seus aliados da véspera e o da defesa do solo pátrio, que em todos os tempos e em todos os povos levantaram os ânimos e galvanizaram as populações.

Comentário à margem esquerda do trecho citado: "Tudo isto vem sendo de uma insensibilidade, de uma incompreensão, de uma falta de Charitas, francamente primárias. E totalitarismo do miúdo.”

(13) p. 109: Cap. X (“A classe”). Nota MA: traço vertical à margem direita da - e traço sublinhando a - frase: "O mito da Classe, aliás, lança suas raízes no passado.”, do trecho:

O mito proletário, que Marx colocou à frente do seu sistema social revolucionário, continua bem vivo em todas as nações, particularmente naquelas que atingiram certo grau superior de motorização. Basta uma centelha para acender incêndios. As massas trabalhadoras dos países altamente industrializados continuam animadas, em grande parte, pelo ideal revolucionário. O mito da Classe, aliás, lança suas raízes no passado.

Comentário à margem direita da frase sublinhada: "Enfim! Mas... Só?..."

(14) p. 110: Cap. X ("A classe"). Nota MA: expoente (1) na p. 10, à margem esquerda do trecho iniciado na página anterior: "O que sucedia apenas é que esses mitos estavam longe de possuir a autonomia que hoje possui o mito da classe proletária, pois as circunstâncias ambientes eram outras." Comentário à margem inferior da p. 10: “A 'autonomia' é absolutamente a mesma. Os processos de obtê-la e conservá-la é que diferem.” 
(15) p. 112-113: Cap. XI (“A nação”). Nota MA: Expoente (1) à margem esquerda do trecho da p. 112: "O fascismo nasceu como reação contra o comunismo. É nesse ponto que se baseia um dos elementos diferenciais com que devemos julgá-lo com objetividade e sem paixão." Comentário à margem inferior da página: "Agora o A. reclama para si o dever de julgar com objetividade e sem paixão...” Em continuação do parágrafo, traço sublinhando o termo "prestou", do trecho: "Historicamente, pode-se dizer que o fascismo foi um erro político que prestou o serviço de combater outro erro político.” Comentário à margem direita do termo sublinhado: “No passado!!!” Ainda no mesmo parágrafo, traço sublinhando o fragmento "com isenção absoluta de ânimo", do trecho:

Se devemos condenar o fascismo como mito político e como instaurador de novos mitos e novas místicas tão destruidores como aqueles que pretendeu destruir e entre os quais acabou se integrando, - não devemos desconhecer, com isenção absoluta de ânimo, a sua posição histórica.

Em continuação do parágrafo, na página seguinte, traços sublinhando o fragmento "negam ao Comunismo, em nome da Democracia" e a frase “Não é fácil, hoje em dia, guardar isenção de ânimo.”, do trecho: "Fazer o contrário é agir como os que tudo negam ao Comunismo, em nome da Democracia, ou os que tudo negam à Democracia em nome do Totalitarismo. Não é fácil, hoje em dia, guardar isenção de ânimo.”

(16) p. 114: Cap. XI (“A nação”). Nota MA: traço vertical à margem esquerda do trecho:

A vitória das Nações-Unidas é tão necessária aos destinos da civilização, como o será depois uma vitória dessas Nações sobre si mesmas e sobre os regimes secularizados e as ideologias erradas que elas absorveram em muitos séculos de descristianização e que foram a raiz de toda a mitologia totalitária de nossos dias.

Comentário à margem esquerda do trecho citado: "Vers l'azur!..."

(17) p. 118-119: Cap. XI (“A nação”). Nota MA: traço sublinhando o trecho:

[Outra feição da mística fascista foi o imperialismo. Os comunistas costumam atribuir ao termo e ao fato do imperialismo uma ori- 
gem e uma função de caráter capitalista.] É completamente falso. O imperialismo é uma expressão natural de todo ser, individual ou social, de toda personalidade forte e de toda civilização poderosa.

Expoente (1) à margem esquerda do trecho sublinhado, para comentário à margem superior da página:

Eis o que é paixão partidária e sectarismo. Não é falso. Ou melhor: é mentira. Um comunista chamará também de manifestação imperialista a conquista da Etiópia. Mas o A. que tudo sumariza, aqui se arrepela com um conceito "histórico" e resolveu "distinguir".

Em continuação, traço em chave à margem esquerda do trecho:

É completamente falso. O imperialismo é uma expressão natural de todo ser, individual ou social, de toda personalidade forte e de toda civilização poderosa. Todo ser tende à expansão. De modo que nenhuma força se limita a conter-se em seu foco original. O que se dá com as forças físicas ocorre com as forças psíquicas e com as forças sociais. É justamente um dos elementos do dinamismo mítico dos nossos tempos. O imperialismo capitalista chamou-se - Colonização. O imperialismo comunista chamou-se Revolução mundial. O imperialismo fascista chamou-se - Império. O imperialismo nipônico chama-se - a Ásia para os asiáticos, isto é, para o Japão... E assim por diante.

No interior do espaço demarcado pela chave, traço vertical à margem esquerda do trecho que vai da frase "De modo que nenhuma força se limita a conter-se em seu foco original." até a frase "E assim por diante.", que finaliza o parágrafo. À margem esquerda do traço vertical e da chave, expoente (2) para comentário que começa à margem inferior da p. 118 e conclui na margem inferior da página seguinte:

É inconcebível a leviandade do A. aqui, que o induz a um erro latifundiário. Dando exemplos verdadeiros e criminosos, o A. justifica [termo sublinhado] o imperialismo como "expressão natural de todo ser individual ou social"!!! O imperialismo não deriva de uma expressão natural do ser, mas do crime do "lobo e o cordeiro". Não é uma “expressão”, é uma “deformação". Onde ficou Cristo! Onde ficou o Sermão da Montanha! Onde ficou o "a César o que é de César”! 
(18) p. 119: Cap. XI (“A nação”). Nota MA: Traço sublinhando o trecho:

Ainda é cedo, naturalmente, para julgarmos acontecimentos tão próximos a nós. E a passionalidade de nossos tempos dificilmente admite esse espírito de distinção, mais compatível com épocas menos belicosas e menos apaixonadas do que a nossa.

Comentário à margem esquerda do trecho citado, concluindo na margem superior da página: "É psicologicamente concludente que ao atacar o Comunismo o A. nenhuma vez se preocupasse em ser honesto e justo e capaz de distinguir, e agora se refira tantas vezes a essas exigências do verdadeiro espírito filosófico.” Em continuação do parágrafo, traço em arco à margem esquerda do trecho:

Em torno do fascismo, portanto, de seus mitos desastrosos do Estado todo poderoso, como instrumento de Poder mais que de Justiça e sua adoração da Nacionalidade como uma mística renovada do paganismo - ainda não é tempo de se pronunciar um julgamento eqüitativo. Dia virá em que a posteridade o faça com mais serenidade do que hoje.

Traço sublinhando o fragmento do trecho anteriormente citado: “ainda não é tempo de se pronunciar um julgamento eqüitativo. Dia virá em que a posteridade o faça com mais serenidade do que hoje." E pequeno traço em arco à margem esquerda da frase do fragmento anteriormente citado: "Dia virá em que a posteridade o faça com mais serenidade do que hoje."

(19) p. 120: Cap. XI (“A nação”). Nota MA: traço sublinhando o trecho: "Tudo isso é bem representativo da atmosfera passional e não racional que respiramos.” Comentário à margem esquerda do trecho citado: "Oh!"

(20) p. 121: Cap. XII (“A raça”). Nota MA: traço vertical à margem esquerda do trecho: "A idéia de Raça parecia morta. No decorrer do século passado todo o determinismo sociológico girou em torno de outro conceito - o do Meio." Expoente (1) à margem esquerda do trecho citado, para comentário à margem inferior da página: "Absolutamente não. E Gobineau? E Chamberlain? E Wagner? De resto não é possível distinguir, no séc. passado, como ideologias perfeitamente distintas uma da outra, racismo e nacionalismo." 
(21) p. 125: Cap. XII ("A raça”). Nota MA: traço sublinhando o trecho: "[O homem era Hitler,] vindo do nada e portanto possuindo, para a tarefa revolucionária, como Mussolini, Lenin ou Stalin, a imensa vantagem da aventura pura.” Expoente (1) à margem direita do trecho citado, para comentário à margem inferior da página: "Ou a libertação das heranças? Queria muito saber o que pensaria disto o filho de carpinteiro de Nazaré. Mas o A. não só confunde Cristo com Civilização Cristã (I. Média), como não raro prefere esta a Aquele."

(22) p. 153: Cap. XIV (“Os contra-mitos de ordem geral”). Nota MA: traço sublinhando o termo "civilização", no trecho: "E nesse caminho, o papel do Brasil poderá ser considerável na elaboração da nova ordem do mundo, pois um dos dados fundamentais da civilização brasileira é o desprendimento natural pelos bens materiais." Expoente (1) à margem direita do termo sublinhado, para comentário à margem inferior da página: “Da ‘civilização' não, da ‘cultura'.”

(23) p. 171-172: Cap. XIV ("Os contra-mitos de ordem geral"). Nota MA: traço vertical às margens direita (p. 171) e esquerda (p. 172) do trecho:

Ora, o pudor é um dos mais nobres atributos da mulher, por estar naturalmente adequado à sua natureza específica. Uma mulher sem pudor é uma mulher diminuída em sua natureza. E portanto uma cultura física que começa por diminuir o próprio objeto que pretende elevar, está viciada em sua fonte. É má, por conseguinte, a cultura física? De modo algum. É útil, necessária, imprescindível. Mister é relacioná-la com uma concepção geral da vida em que não se faça do corpo humano um ideal ou um ser em si.

Traço sublinhando o fragmento "naturalmente adequado à sua natureza específica” e exclamação à sua margem esquerda. Expoente (1) à margem esquerda do trecho supracitado, para comentário à margem inferior da página: “Tudo isto é a ignorância voluntária do quanto se tem estabelecido de 'verdade' a respeito do pudor na natureza humana. Mas o cômico é que pro A. o pudor não é um ‘atributo' do ser, mas da mulher!”

(24) p. 173: Cap. XIV (“Os contra-mitos de ordem geral”). Nota MA: comentário à margem inferior do parágrafo: 
Por isso dizíamos de início que a volta a Deus é o fundamento de toda cruzada anti-mitológica. Se queremos transformar o culto da cultura, numa atividade cultural realmente fecunda, saibamos reintegrar a verdade, - que leva o homem do culto de si mesmo ao culto autêntico a Deus, único fim último e absoluto de sua personalidade e de suas atividades, - na posição de retificadora de toda cultura. E teremos arrancado a esta dos domínios de uma falsa mística, para a colocarmos no posto que lhe compete, na formação integral da personalidade humana. E com isso de uma civilização realmente superior. Não é o número de escolas, nem o número de livros, nem a quantidade maior ou menor de analfabetos que marca a colocação de um povo na escala da civilização. É a qualidade dos seus homens. E a natureza de sua cultura, na hierarquia natural dos valores.

\section{Comentário:}

Tudo isto é de um confusionismo... É possível a um analfabeto, por ex., atingir esta "qualidade" que o A. deseja aos homens!... É o próprio São Tomás, numa frase de horrenda e trágica verdade, que já nos disse atrás que pra o homem conseguir uma vida moral, precisa de um certo número de bens materiais.

(25) p. 182: Cap. XV (“Os contra-mitos de ordem política”). Nota MA: traço sublinhando o fragmento: "a ausência do espírito de distinção”, do trecho iniciado na página anterior:

Não nos defrontamos, portanto, com uma simples manifestação de intelectuais esquerdistas, por mais que a maioria assim o seja. A não ser que se atribua ao termo esquerdista, como se ouve por vezes em certos arraiais, um significado generalizador e polêmico, que sofre daquele mal tão corrente em nossos dias - a ausência do espírito de distinção.

Comentário à margem esquerda do fragmento sublinhado: "!ah!”

(26) p. 190-191: Cap. XV (“Os contra-mitos de ordem política”). Nota MA: expoente (1) ao final do parágrafo: 
Aqui desejo apenas acentuar que o pan-eslavismo, que se desenvolveu a partir de certa fase da Revolução Soviética ou antes que se integrou na Revolução Comunista, formando com ela uma estranha simbiose, na base de um messianismo ao mesmo tempo racial e institucional - o pan-eslavismo está hoje confundido com o sovietismo. Mas possui um caráter essencialmente racista e muito anterior ao do germanismo hitlerista, que só o assumiu em fase relativamente recente da sua Revolução.

Comentário à margem inferior da p. 190, continuando às margens inferior, direita e superior da p. 191:

Aqui a injustiça da generalização chega ao absurdo, a não ser que o A. esteja mentindo - o que talvez seja preferível imaginar! Dar ao sovietismo "caráter essencialmente racista" e o que é mais idiota pan-eslavista, o confundir com o pan-germanismo racista, que o A. insiste em justificar (é o termo doloroso) como nascido de uma necessidade contra a Revolução (quando ele mesmo lhe reconheceu causas de origem histórico-psicológicas: tudo isso é confundir atualidade histórica com falsa profecia. Profecia falsa que nem os dados da Espanha, da China, do México justificam sequer. De resto, o mal demagógico infelizmente revestido de Cristianismo, ou simplesmente de Filosofia, de toda a pregação idealista desta parte, é que o A. não enxerga o homem, mas sonha com o Homo. E o que é mais idílico, mas apenas idílico, um Homo dotado de historicidade, um sonho do Homo pré-renascente, pré-rafaelista, ao mesmo tempo que esquece toda a história do homem, anterior a Cristo e posterior à Civilização Cristã. Nunca o A. abusou tanto da verdade e da filosofia pra criar um sonho não apenas improvável: absolutamente vão.

(27) p. 190: Cap. XV (“Os contra-mitos de ordem política”). Nota MA: traço sublinhando o fragmento: "um semitismo tão racista como o germânico e tão místico, como o anti-semitismo.”, do trecho:

A perseguição anti-semita, que atingiu na Alemanha hitlerista um caráter de tal odiosidade que despertou um sentimento universal de simpatia pelos judeus, não nos deve fazer esquecer que existe um semitismo tão racista como o germânico e tão místico, como o anti-semitismo. 
Comentário iniciado à margem esquerda do fragmento sublinhado, até a margem superior da página:

Oh, meu Deus! Mas que generalização malvada! E sectária! Não nego um semitismo, mas o A. nega toda a história nesta igualação, palavra-de-honra, desavergonhada! Mas a Idade-Média é uma espécie de ideal para o A., como lembrar os guetos?

(28) p. 191: Cap. XV ("Os contra-mitos de ordem política"). Nota MA: traço sublinhando os termos "caso Drumond", do trecho iniciado na página anterior: “A fobia anti-semita que há meio século era limitada a pequenos círculos intelectuais e políticos, como se viu no caso Drumond em França - essa fobia anti-semita, errada e injusta, adquiriu hoje um caráter universal." O traço sob os termos prolonga-se verticalmente para baixo, à sua margem esquerda, com o comentário: "Dreyfus!!"

(29) p. 192: Cap. XV (“Os contra-mitos de ordem política”). Nota MA: traço em colchete à margem esquerda do trecho da nota (4): "Essa tendência a equiparar filhos legítimos, naturais e até adulterinos é uma tendência francamente totalitária." A base do colchete prolonga-se horizontalmente à margem esquerda do trecho citado, com o comentário: "É preceito simplesmente cristão, que, aliás, como igualdade humana, nada tem a ver com a Família, nem a destrói."

(30) p. 193: Cap. XV (“Os contra-mitos de ordem política”). Nota MA: traço sublinhando os termos "único concorrente", do trecho iniciado na página anterior:

Daí ser a verdadeira luta da Alemanha de hoje a luta contra a Inglaterra. Não só é seu maior adversário - como heroísmo, como tenacidade, como gênio organizador, como força de instituições, como amor da independência e como tradição imperial - mas ainda seria o seu único concorrente na dominação do Ocidente, se a Rússia fosse afastada.

(31) p. 195: Cap. XV (“Os contra-mitos de ordem política”). Nota MA: traço em chave à margem direita do trecho: 
O problema da Igreja é hoje um daqueles nos quais a solução mais viável não é a solução perfeita, dado o fato lamentável mas inegável da perda da unidade da Fé. De modo que a Igreja Católica, a quem caberia por direito divino a prioridade e a univocidade no governo espiritual da sociedade, vê-se hoje forçada pelas circunstâncias a reivindicar apenas a sua liberdade contra os seus inimigos e contra alguns dos que alegam ser seus amigos e de fato pretenderiam oprimi-la sob pretexto de a defender, como tantas vezes sucedeu no curso da história.

Comentário à margem direita do trecho citado: "Eis que o A. se torna histórico, relativista e pragmático. E se quer filósofo em busca da Verdade."

(32) p. 217: Cap. XVI ("Nacionalismo e patriotismo"). Nota MA: traço vertical à margem direita do trecho da citação de Jacques Maritain na nota (28), p. 217, concluindo na página seguinte:

Num terceiro sentido enfim, a palavra nacionalismo pode designar a forma corrompida do nacionalismo legítimo, como o definimos de início, e é então o culto cego da nacionalidade, cidade ou pátria, tomada como superior a toda lei moral e religiosa, o nacionalismo por oposição a Deus e ao Reino de Deus; quer recuse reconhecer a independência da Igreja de Cristo e seu poder sobre as coisas temporais, poder de cuja extensão só a Igreja é juiz em cada caso e que lhe permite desligar de seu juramento de fidelidade os súditos de um príncipe apóstata; [...]

Comentário à margem inferior da p. 217: "Parece incrível que o A. cite isto, que não é nem histórico, nem relativista nem pragmatista, elogie a sua clarividência e legitimidade, depois do que escreveu na p. 195.” [N.B: Cf nota de MA à p. 195].

(33) p. 223: Cap. XVI ("Nacionalismo e patriotismo”). Nota MA: traço em "L" à margem direita do trecho: "Todos os seres vivos nascem, mas só o homem ama o lugar em que nasceu." Comentário à margem direita do trecho citado: "não é cientificamente verdade".

(34) p. 232: Cap. XVI (“Nacionalismo e patriotismo”). Nota MA: aposição da letra "s" em "resto", do trecho: "Esse mesmo vago espiritualismo deista ia encontrar o seu túmulo com o naturalismo e o cien- 
tificismo do século XIX, que iam dar o golpe de misericórdia nos últimos resto[s], do espiritualismo anacrônico."

(35) p. 233: Cap. XVI ("Nacionalismo e patriotismo"). Nota MA: traço sublinhando o fragmento "tornou muito ambígua a expressão", do trecho:

Temos finalmente os cristãos. Já disse que não é nunca sem grande hesitação que emprego esse termo, não só porque a ruptura da cristandade tornou muito ambígua a expressão, mas ainda porque ninguém saberá jamais, nesta vida, quando pode realmente aplicar essa designação a quem quer que seja.

Comentário à margem direita do fragmento citado: "Quem o diz!"

(36) p. 234: “Conclusão". Nota MA: traço sublinhando o segundo termo "infinita”, do trecho: "A vida cristã no mundo é e será sempre uma oscilação, ao mesmo tempo desolada e alegre, entre uma presença infinita e uma infinita ausência." Expoente (1) à margem direita do termo sublinhado, para comentário à margem inferior da página: "Infinita? 'Constante' seria o termo."

(37) p. 235: "Conclusão". Nota MA: traço sublinhando os termos "procurar compreender", do trecho:

Por isso mesmo é que não podemos cruzar os braços ante a mitologia dos nossos tempos e temos o dever de procurar compreender e quanto possível atenuar a grande miséria dos homens e a grande tragédia dos mitos contraditórios e das místicas desvairadas.

(38) p. 235: “Conclusão”. Nota MA: três exclamações à margem direita do trecho:

E todo aquele que não se sentir totalmente ausente de tudo o que for apenas deste mundo não conhecerá jamais a doçura da verdadeira paz do espírito, nem o segredo das relações verdadeiras e salvadoras. A vida está na morte, a riqueza na pobreza, a vitória na derrota, a fecundidade dos frutos no apodrecimento das sementes. 
(39) p. 236: “Conclusão”. Nota MA: traço vertical e exclamação à margem esquerda do trecho:

Quando propomos, portanto, os contra-mitos contra os mitos que dominam os nossos tempos, não temos a mínima ilusão de poder conseguir, com eles, uma Idade Nova paradisíaca para o dia em que a Guerra terminar e os totalitarismos sejam domesticados e as democracias purificadas por um batismo de bom senso humano e de graça divina. As civilizações serão eternamente uma vaga e remota imagem de um Reino que não é deste mundo.

(40) p. 237: "Conclusão". Nota MA: traço sublinhando o - e exclamação à margem direita do - fragmento: "coragem invencível e a paciência dos que vivem na Alegria perfeita da renúncia.”, do trecho iniciado na página anterior: "Contra o orgulho e a vaidade dos Mitos do nosso tempo, tenhamos a coragem invencível e a paciência dos que vivem na Alegria perfeita da renúncia."

(41) p. 237: "Conclusão". Nota MA: traço sublinhando o trecho: "Porque a herança do Pecado feriu de morte todas as almas, até à liquidação dos tempos.” Comentário à margem inferior da página, continuando nas duas páginas em branco seguintes:

Eis no que dá uma atitude "cristianica" (não, de Cristo), regularmente... luterana até, e pelo menos muito pascaliana [fragmento riscado] diante do terrível problema da realidade terrestre do homem social. Um capítulo que não deixa de ter a sua poesia, mas de um confusionismo assombroso. Como negar que o apostólico A., se colocando bonitamente entre os insatisfeitos, no fundo é um satisfeito, e um fatalista. É quase repulsivo observar como o A. insiste, no meio das suas tiradas fatalistas sobre a felicidade e o Bem Supremo não serem deste mundo, é quase repulsivo observar como, sem a menor ordem lógica de pensamento, ele volta a falar nos mitos e no combate aos mitos. É uma insistência meramente psicológica. Uma como consciência pré- ou supraconsciente de que estava fora do assunto, fora da atitude lógica, fora da Filosofia.

É impossível negar que o A. lida com inúmeras verdades e as proclama por todo o livro. Mas é isso mesmo que torna o livro mais inaceitável! Misturada de verdade e pietismo quase supersticioso enquanto aplicado à realidade. $\mathrm{O}$ autor avisa e sabe que uma civi- 
lização nova está nascendo. E, idealistamente, não cuida de orientá-la, a nega. Não é uma atitude filosófica, é uma atitude pietista, muito bem alicerçada em sã filosofia. Mas recusando desta, de São Tomás como de Maritain, o não-conformismo "infinito", a luta, a ação verdadeira. Não basta o alicerce. O A. constroe uma Torrede-Pisa, na iminência eterna de cair. Os próprios contra-mitos, quase sempre legítimos que propõe, se tornam ideais hierárquicos e aristocráticos, sem a menor força de fecundidade. Fecundidade terrestre e social.

De forma que, entrançado, emaranhado em verdades incontestáveis - ou simplesmente, na Verdade - a atitude do A. e suas conseqüências não são nem filosóficas nem de fato cristãs. Parece mesmo que o A. confunde bastante apostolado com missões pra cristianizar chins ou tupis. A verdadeira atitude católica social, não pode nunca ser condicionar a vida terrestre a uma imperfeição irremediável e ao "Pecado que feriu de morte todas as almas". É inaceitável esta atitude confor[mista], fatalista e... burg[ues]a, como ver[dade] [apostó]lica a atitude católica tem de ser [demo]crática: a Igreja não pode abandonar os seus direitos sobre as sociedades dos homens. É a atitude de Maritain e é a verdadeira. E como verdade tout court, que não deixa de ser também católica, é uma atitude de ação, como diz o A., mas que não pode preliminarmente contar com a precariedade terrestre do Homem, embora saiba dela. A ação, o Bem, é atingir a perfeição social. A perfeição - sem imaginar que ela não pode ser alcançada. O homem indivíduo tem como absoluto dever moral atingir o Bem, ou mais completamente, a Perfeição que inclui a Verdade e o Belo. Pouco importando a revelação de que isso é um prêmio da vida futura. O homem social tem esse mesmo absoluto dever moral em relação à sociedade $\mathrm{e}$ à Terra. A Lei admirável e inefável é que não há (não devia haver...) acomodações com a Igreja. Tudo o mais é conformismo e fatalismo pietista. E um idealismo empalamado. Livro que causa um malestar enjoativo. Não pelo que recusa, quase sempre. Mas, quase sempre, pelo que aceita.

Ao fim do trecho, dois traços paralelos em diagonal. 